\title{
Research and Practice of Innovation and Entrepreneurial Education Model of Computer Major
}

\author{
Jing Li \\ Xi’an Peihua University, Xi’an, Shaanxi, 710125
}

Keywords: research; practice; innovation and entrepreneurial education model; computer major

\begin{abstract}
The society is developing and the times is advancing. In the course of development in recent years, China's higher education has also undergone tremendous changes. The computer education model of colleges and universities has ushered in an unprecedented challenge. Computers break through traditions and strive for more effective teaching results and teaching must find the most effective innovation and entrepreneurship model. This paper will conduct in-depth analysis and inquiry into the innovation and entrepreneurship education model for college computer students.
\end{abstract}

\section{Introduction}

The modern people's life is inseparable from the Internet. However, in many colleges and universities, the emphasis of the undergraduate course in computer science is still the study of theoretical knowledge, and there is a lack of education for innovative knowledge and entrepreneurial markets. The contents and methods of undergraduate education in the traditional sense can no longer meet the needs of the society for talents. The study of professional courses and the study of entrepreneurship education have not been synchronized. Therefore, how to better cultivate and motivate the creative potential of students according to the needs of socio-economic development combined with the background of transformation and development has become a problem that contemporary colleges and universities urgently need to think about and solve [1].

\section{Problems in Innovation and Entrepreneurship Education for Computer Majors in Colleges and Universities}

At present, many colleges and universities are still paying too much attention to the employment of university graduates. This directly leads to a higher proportion of innovation and entrepreneurship education work that has not received due attention. Some teachers and school students have failed to correctly establish the concept of entrepreneurship and innovation education, resulting in an excessive education model. In fact, the goal of organizing innovation and entrepreneurship education is not simply to cultivate a large number of outstanding entrepreneurial talents, but to cultivate a group of talented entrepreneurial talents, which can quickly digest and absorb advanced culture and ideas and break through the constraints of traditional cultural ideas. For this reason, universities and colleges should place innovation and entrepreneurship education in the same important position as professional education. When carrying out specific tasks, universities and colleges should have their own characteristics. They should use relevant policies as standards, choose the most suitable method to carry out innovation and entrepreneurship education in accordance with their own level of strength, and promote students to achieve overall improvement.

At present, the computer major has already become the public major of major universities in China. The difference is that the characteristics of different universities and colleges are different, so the goal of personnel training is bound to be different. According to the nature of computer professional work can be divided into applications, engineering and research and other fields. Taking the software major of a university as an example, its talent training goal is set to create applied talents with excellent quality, high morality, solid theory, excellent foundation, excellent 
research and development and implementation capabilities, coordination and communication skills, and strong practical ability. However, the goal setting does not cover the content of innovation and entrepreneurship education. This type of goal is unreasonable and cannot be fully compatible with innovation and entrepreneurship education. Therefore, it has hindered the continuous and comprehensive development of the latter [2].

From the perspective of China's current innovation and entrepreneurship education training teachers, many higher education institutions generally lack teaching talents with both theoretical knowledge and practical experience. In fact, the effective development of innovation and entrepreneurship education can not be separated from the core of the teaching staff. The main way to train talent is through teachers. At present, the development of the innovation and entrepreneurship education faculty in China is still in a stage of gradual growth. Some college teachers are usually research-oriented teachers. They have outstanding achievements in academics, but their ability to innovate and innovate has always been lacking, and good self-development cannot be completed. On the other hand, some teachers with higher innovation and entrepreneurship have rich practical experiences, but they cannot obtain the recognition of university education and scientific research. At the same time, for these teachers themselves, they are more inclined to engage in their own business ventures and do not want to. How much has developed in colleges and universities. Some colleges and universities innovative and entrepreneurial education team teachers are more allocated from the administrative management department, professional theoretical knowledge is not enough to support practical work, although after training can make up for deficiencies, but the entrepreneurial practice experience has always been inadequate. The organization of innovative entrepreneurship courses mostly explains theoretical knowledge and lacks deeper practical skills. 2. Research status of innovation and entrepreneurship education at home and abroad

The concept of entrepreneurship education in foreign countries can be traced back to the pioneering course offered by the Harvard Business School in 1947. In 1953, Drucker opened the "Entrepreneurship and Innovation" course at New York University, marking the rise of entrepreneurship education in the United States aimed at cultivating students' self-employment ability. In the 1980s, entrepreneurship education began to break through the scope of business schools and faced all disciplines. Japan, Britain, Germany, and other developed countries also began to introduce entrepreneurship education. In 1988, the "21st Century Declaration of Higher Education: Prospects and Action" adopted by UNESCO at the first World Conference on Higher Education held in Paris, France, states: "In order to make graduates employable, higher education should mainly cultivate entrepreneurial skills and initiative. Graduates will not only be job seekers, but above all job creators.” The U.S. college business education curriculum has already formed a complete system. In addition to the comprehensive entrepreneurial education such as Baxter College and Harvard Business School, Massachusetts Polytechnic University, University of California, Berkeley, etc [3]

China has integrated the concept of innovation into entrepreneurship education and put forward the concept of "innovation and entrepreneurship education." In 2002, the Ministry of Education determined that 9 universities, including Tsinghua University and Beijing University of Aeronautics and Astronautics, took the lead in piloting innovation and entrepreneurship education. In 2008, the Ministry of Education passed 30 experimental zones for the training mode of innovation and entrepreneurship education [4]. In 2010, the Ministry of Education issued the "Opinions on Vigorously Promoting Innovation and Entrepreneurship Education in Colleges and Universities and Self-starting Work for University Students”, and China's innovation and entrepreneurship education has entered a new stage of development.

\section{Implementation Strategy of Innovation and Entrepreneurship Education for Computer Majors in Colleges and Universities}

All along, under the constraints of exam-oriented education, our country has made contemporary students have a solid foundation of basic knowledge and a lack of practical ability for innovation 
and entrepreneurship. At the present stage, the era dominated by the knowledge economy system puts forward new requirements for higher education in China. Talents cultivated in colleges and universities in China should not only possess solid theoretical knowledge, but also have a scientific outlook and social responsibility. There should be some practical and innovative capabilities, which means that students must accept innovation and entrepreneurship education. Innovation and entrepreneurship education puts the improvement of college students' ability in innovation and entrepreneurship at the top of the list. This will be of great help to the improvement of college students' social experience and self-literacy. Students must develop their ability to apply innovative and entrepreneurial skills to their daily practice. Get to know yourself well and improve your quality. The cultivation of innovative and entrepreneurial abilities is not accomplished overnight. It takes a long time to learn and is a systematic project. Therefore, innovation and entrepreneurship education must be used to influence the teaching concepts and concepts of universities and colleges. At the same time, the professional basic knowledge has also included innovation and entrepreneurship education within the teaching objectives, and has carried out all-round reforms in the innovation and entrepreneurship teaching model of computer science.

Innovation is the basic requirement for talents in the computer industry. Computer technology needs constant innovation in order to continue to adapt to the needs of social development and continues to grow. Therefore, computer science must continue to inspire students' innovative ability and awareness through innovation and entrepreneurship education. Based on the concept of computer professional education, and on the premise of changing teaching ideas and teaching concepts, we help students to create innovative, entrepreneurial education for personnel, and combine computer education concepts with innovation and entrepreneurship education concepts to develop teaching. The correct idea is the beginning of a good way of action, and the mode of action directly affects the learning effect. The correct teaching concept will guide the correct teaching action and eventually form the teaching result of the university. Therefore, in the process of computer professional innovation and entrepreneurship education, we must first deeply understand the relevance between computer professional education and innovation and entrepreneurship education, so that a single computer professional teaching theory is fully updated and optimized to improve students' sense of social responsibility and entrepreneurship The main purpose of entrepreneurial ability is to focus on reforming the talent training methods in colleges and universities to form a teaching philosophy that combines computer professional education with innovation and entrepreneurship education [5].

The most fundamental purpose of college education is to cultivate students' potential and ability for self-learning and development. The fundamental purpose of innovation and entrepreneurship education is to cultivate and improve students' innovation and entrepreneurship, and to have the awareness and ability of entrepreneurial planning and self-employment. A clear talent training goal can make computer professional education and innovation and entrepreneurship education more effective. Therefore, colleges and universities should update the current training objectives of computer professionals as soon as possible, and introduce the goals and objectives of innovation and entrepreneurship education, so that the goal of computer professional training and the goal of innovation and entrepreneurship education get rid of the previous contradictions. For example, the goal of cultivating talents in computer science in China's general colleges and universities is expressed as follows: Through various educational activities, students are provided with solid basic knowledge of computer theory and professional skills. They have a certain sense of innovation and ability. They are good at analyzing the computer industry. There are potential business opportunities, a certain degree of coordination and leadership, and a challenging spirit in solving problems.

In the process of innovation and entrepreneurship education in colleges and universities, the strength of teachers is the most crucial influencing factor. Schools must continuously optimize the introduction and training system for computer innovation and entrepreneurship teachers, and establish a high-quality, quantitative innovation and entrepreneurship education teacher team through a reasonable election mechanism. First of all, for some full-time innovative and entrepreneurial teachers, the school can not only introduce some outstanding innovative and 
entrepreneurial talents from the society, but also can establish cooperative relationships with some computer companies so that some entrepreneurs can enter the campus and become part-time teachers, bringing more benefits to students. As we all know, there are no shortages of successful entrepreneurs in the field of computer science in China. Schools can invite such individuals to come to the school to serve as part-time teachers or lecturers, impart rich and practical entrepreneurial experiences to students, and share teaching experiences with full-time innovation and entrepreneurship teachers. Followed by computer professional teachers, the school can bring together all professional teachers to conduct entrepreneurship training courses, to improve the basic knowledge of full-time teachers. Schools should strengthen funding and policy support in scientific research, encourage teachers to conduct more scientific research activities, and participate in various types of seminars conducted by the computer industry so that only innovative and entrepreneurial teachers are constantly updated and enriched in their architecture and systems, and keep up with the latest scientific trends. . Finally, the relevant personnel of the administrative management department, from the surface, the staff of the administrative department rarely ties up with the school's innovation and entrepreneurship education work, but as the school administrative management department, it has direct influence on the development trend of the school and the specific work. As a result, the professional teacher's ability to train should also be ensured. The staff of the administrative management department should also be provided with relevant innovation and entrepreneurial knowledge training. Through training, the connotation of innovation should be reflected in student management and campus management. The management level of the entire school rose. In addition, schools should regularly perform performance appraisal on innovation and entrepreneurship educators. Through this assessment method of survival of the fittest, the innovative and entrepreneurial teachers of computer professionals will be ensured.

The computer professional innovation and entrepreneurship ability training curriculum should be developed in the direction of general education curriculum, and the innovation and entrepreneurship courses designed in some professional courses should be integrated to establish a set of multi-functional curriculum systems with interpenetrating functions. First of all, schools should actively carry out the construction of innovative and entrepreneurial courses. According to the types and characteristics of innovation and entrepreneurship courses, relevant compulsory courses and elective courses should be set up separately. Compulsory courses and elective courses should be managed separately. Compulsory innovation and entrepreneurship courses should focus on innovation and entrepreneurship. The basic theoretical knowledge is introduced to cultivate students' awareness of innovation and entrepreneurship, while elective courses should focus on the cultivation of individual innovation and entrepreneurship education, and strive to improve students' innovative entrepreneurial ability. Secondly, all existing public courses should be improved. The public course system is still relatively complete at this stage. Schools can use the concept of innovation and entrepreneurship to optimize these public courses on the basis of the original and incorporate more innovations. Finally, efforts should be made to make interactions and interactions between innovation and entrepreneurship courses and professional courses, and to add more innovative and entrepreneurial education elements to professional courses to promote the improvement of professional course systems.

\section{Conclusion}

In summary, in the education and teaching of institutions of higher education, the important role played by the innovation and entrepreneurship education model is that any other education model has no substitute and beyond. The comprehensive application of the innovation and entrepreneurship teaching model has, to a large extent, promoted the improvement of the teaching methods and methods of professional teachers. It has also truly influenced the teaching concepts of teachers and greatly improved the quality of computer professional teaching, so that students of computer science are also With comprehensive and effective development, the innovative and entrepreneurial education model cultivates the computer-based high-end talents required by today's society. It also provides more and more human resources for the development and progress of 
society. It will inevitably promote our country's development. The teaching of computer science in colleges and universities has embarked on a higher level.

\section{References}

[1] WANG Caihua, LI Fujie. The Experience and Enlightenment of Entrepreneurship Education in American Universities [J]. Chinese Journal of Higher Education Research, 2008, 27(5): 92-96.

[2] Chen Xi. Innovating Entrepreneurship Education throughout the Process of Talent Cultivation in Colleges and Universities [J]. China Higher Education, 2010(12): 4-6.

[3] Liu Wei. Thoughts on the Construction of Innovative Talent Training System in Colleges and Universities [J]. Education Science, 2011, 27(5): 64-67.

[4] $\mathrm{Hu}$ Tao, Shen Li. The Enlightenment of Foreign Innovative and Entrepreneurial Education Models to Chinese Universities [J]. China University Teaching, 2013(2): 91-95.

[5] Fang Shujian, Zhu Xifang, Wu Ting. On the Construction of Innovation and Entrepreneurial Education System in Colleges and Universities [J]. Journal of Changzhou Institute of Technology: Social Sciences, 2011, 29(3): 103-107. 